\title{
Factors associated with chemsex in Portugal during the COVID-19 pandemic*
}

\author{
Jeremias Salomão Chone ${ }^{1}$ \\ (D) https://orcid.org/0000-0002-6212-723X \\ Shirley Verônica Melo Almeida Lima² \\ (D) https://orcid.org/0000-0002-9062-0742 \\ Inês Fronteira ${ }^{1}$ \\ (D) https://orcid.org/0000-0003-1406-4585 \\ Isabel Amélia Costa Mendes 3,4 \\ (D) https://orcid.org/0000-0002-0704-4319 \\ Ahmed Nabil Shaaban ${ }^{1}$ \\ (D) https://orcid.org/0000-0001-8483-638X \\ Maria do Rosário Oliveira Martins ${ }^{1}$ \\ (1) https://orcid.org/0000-0002-7941-0285 \\ Álvaro Francisco Lopes Sousa1,3,4 \\ (D) https://orcid.org/0000-0003-2710-2122
}

This article was originally made available as a preprint, with DOI no 10.1590/SciELOPreprints.1524.

1 Universidade Nova de Lisboa, Instituto de Higiene e Medicina Tropical, Global Health and Tropical Medicine; Lisboa, LS, Portugal.

2 Universidade Federal do Sergipe, Departamento de Enfermagem, Lagarto, SE, Brazil.

3 Universidade de São Paulo, Escola de Enfermagem de Ribeirão Preto, PAHO/WHO Collaborating Centre for Nursing Research Development, Ribeirão Preto, SP, Brazil.

${ }^{4}$ Scholarship holder at the Conselho Nacional de Desenvolvimento Científico e Tecnológico (CNPq), Brazil.
Objective: to investigate the factors associated with the practice of sex under the influence of drugs (chemsex) among Portuguese men who have sex with men during the period of social distancing to prevent the COVID-19. Method: online survey applied in May 2020 to a sample of 1,301 participants living in Portugal, recruited according to Respondent Driven Sampling and via social media Facebook ${ }^{\circledR}$. Descriptive and bivariate analyses were performed along with logistic regression to calculate adjusted Odds Ratio (ORa). Results: the prevalence of chemsex was $20.2 \%$. The likelihood of practicing chemsex increased with group sex (ORa: 28.4, 95\%CI 16.93-47.49); unprotected sex (ORa: 7.1 95\%CI 4.57-10.99); the use of pre-exposure prophylaxis (PrEP) to prevent COVID-19 (ORa: 4.2, 95\%CI 2.71-6.39) and COVID-19 testing (ORa: 1.9, 95\%CI 1.15-3.10). Conclusion: the practice of chemsex among men who have sex with men during the COVID-19 pandemic in Portugal was very frequent and may support greater understanding of the role and impact of sexual behavior on the COVID-19 transmission rates and the current pandemic situation in Portugal.

Descriptors: Sexual and Gender Minorities; Coronavirus Infections; Public Health Nursing; Pandemics; Sexual Behavior; Illicit Drugs.

\section{How to cite this article}

Chone JS, Lima SVMA, Fronteira I, Mendes IAC, Shaaban AN, Martins MR, Sousa AFL. Factors associated with chemsex in Portugal during the COVID-19 pandemic. Rev. Latino-Am. Enfermagem. 2021;29:e3474. [Access 


\section{Introduction}

Cases of respiratory infection of unknown origin were first reported in December 2019 in Wuhan, capital of the Hubei province, China and was later named COVID-19

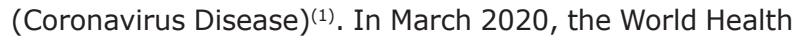
Organization (WHO) considered it a pandemic, and by December 2020, the disease had spread to approximately 218 countries/territories ${ }^{(2)}$. Transmission of the causative virus, the Severe Acute Respiratory Syndrome Coronavirus 2 (SARS-CoV-2), mainly occurs through respiratory droplets and containment and mitigation measures (e.g., social distancing, social isolation and quarantine) and the use of face masks are the primary strategies to prevent infection $^{(3-4)}$.

In some countries, mitigation measures were rigidly and effectively implemented, as was the case of Portugal(5-6). This European country acted early against the SARS-CoV-2 threat. The first cases of COVID-19 were recorded on March $2^{\text {nd }}, 2020$ and 15 days later, the borders with Spain, a country facing one of the worst situations of the pandemic at the time, were closed and the faceto-face teaching was suspended in schools. Days later, the Portuguese government issued a state of emergency and imposed restrictions on people's circulation, social interaction, and religious services, a total ban on beaches, the closure of non-essential activities and the home office regime was adopted, while new sanitary rules were imposed for the businesses that remained open ${ }^{(5-7)}$. Until the end of August, Portugal recorded 58,243 confirmed cases and 1,824 deaths caused by the COVID-19; the incidence rate was 573.5 per 100,000 inhabitants ${ }^{(8)}$, which was pointed out as a case of relative success in comparison to the European Union and at a worldwide level.

However, the successful strategy was not repeated when a second epidemic wave emerged in which these figures grew vertiginously, with 3,549 new deaths and 282,044 new cases recorded up to December $2020^{(9)}$. The country's initial success in fighting the pandemic's first wave was partially attributed to the population's ability to adhere to the government's mitigation measures. However, studies ${ }^{(10-11)}$ show that some population groups may have failed in adhering to these measures, such as the population of men who have sex with men (MSM).

Because it is a population historically marginalized and its sexual practices are socially rejected, its activities are restricted to invisible/hidden places. For this reason, the social support provided by peers might be even more critical and necessary. It would be why this population does not fully adhere to social isolation measures and maintain risky sexual behaviors. Such behaviors significantly increase the likelihood of being infected by the SARS-CoV-2 and should be better clarified ${ }^{(9)}$.

These behaviors include chemical sex or sex under the influence of drugs(10-12), commonly called "chemsex", an association between the words chemical and sex. This practice is a common phenomenon in the community of men who have sex with men ${ }^{(13)}$ and has received particular attention in the field of Public Health due to its growing prevalence among MSM in both developed $^{(13)}$ and developing countries ${ }^{(14)}$.

The type of drugs used in chemsex varies according to each country's specificities and context; however, the literature ${ }^{(15-16)}$ reports that the most prevalent illegal drugs are: methamphetamine, poppers, gamma-butyrolactone (GHB/GBL), crystal methamphetamine, cocaine, erectile dysfunction drugs, ketamine, ecstasy, amphetamine, mephedrone and cannabis/marijuana. Drugs can be consumed in isolation or combined, which increases the potential risk of overdose and chemical dependency among users ${ }^{(17)}$.

Depending on the substance used, the perception of risk and adoption of protective measures may be impaired $^{(18)}$ and as suggested by a multi-center study ${ }^{(11)}$, investigating the practice of chemsex among MSM during social distancing can provide important information regarding the emergence and rapid growth of new cases of COVID-19 in Portugal, a subject that has not been explored thus far.

In this context, this study's objective was to investigate the factors associated with the practice of sex under the influence of drugs (chemsex) among Portuguese men who have sex with men during the period of social distancing to prevent the COVID-19.

\section{Method}

\section{Study design}

This online survey is part of a macro-project called "40TENA", derived from the cohort "In_PrEP Brazil/ Portugal", and was conducted in Portugal and Brazil, led by the Portuguese Institute of Hygiene and Tropical Medicine (IHMT) in partnership with the University of São Paulo (USP).

\section{Study setting and period}

The study was conducted in 15 out of the 18 districts in Portugal in May, 2020 at the peak of the COVID-19 pandemic, when Portugal was under restrictive sanitary measures (social distancing and isolation and mandatory quarantine) advising the population to shelter at home and avoid interactions with people outside their household as much as possible. 


\section{Sampling and participants}

A standard sampling calculation for proportions was performed using G Power (version 3.1.9.7)(19), considering the population of Portuguese men over 18 years of age with an assumed prevalence of $50 \%$ to maximize the sample, also considering it is a new phenomenon and there were no data concerning its prevalence) ${ }^{(20)}$ with a tolerable standard error of $3 \%$ and a confidence level of $95 \%$, the final sample was 1,301 MSM.

\section{Data collection}

The participants were recruited using snowball sampling adapted to the virtual environment(11-12,21). In this method, the participants are responsible for recruiting other individuals with similar characteristics using social media. Fifteen MSM with different social and economic characteristics (commonly related to selection bias) were initially selected considering: country's region, race (Caucasian and non-Caucasian), age (young, adult or elderly) and educational level. These participants, called seeds, received a link that granted access to the survey after they provided their consent to participate. They were asked to invite other MSM from their social network to participate. Two of the most popular worldwide geo-based dating apps (Grindr and Hornet) were used to identify the initial seeds ${ }^{(21)}$. The individuals were approached via online chat and data were collected by adapting the Time Location Sampling (TLS) technique to the virtual environment. The researchers purposely modified their location in the application for the regions selected to access a given area's users, following the methods previously described(22-24).

The researchers also promoted the survey on Facebook ${ }^{\circledR}$, directing it to the MSM population aged from 18 to 60 years old (a Facebook-imposed age restriction), using a fixed post on the official page of the survey (https:// www.facebook.com/taafimdeque/), accompanied by an electronic link that granted access to a Free and Informed Consent Form (FICF) and the survey's questionnaire. This procedure is essential to ensure that MSM living outside large cities or metropolitan areas are included(23).

Only individuals who identified themselves as men (cisgender or transgender), $18+$ years old and residing in Portugal were included; non-Portuguese speakers or tourists were excluded.

The online form was hosted by a specific data collection site that enabled only one response per IP (internet protocol), i.e., only one response per electronic device, to avoid selection bias. The form was content validated $^{(25)}$ by three expert/specialist in the topic and was divided into four sections with 46 questions, most were multiple-choice questions, and some were mandatory; without answering those questions, the participant could not proceed with the questionnaire. The questions addressed social and demographic information (age, education, gender identity, housing and type of relationships, according to prior studies) (10-11,26-27), mental health (self-perception of stress and strategies to cope with the pandemic), behaviors adopted to protect against the pandemic (social distancing, protective measures against the COVID-19 and level of adherence) and sexual behavior during the social distancing, isolation or quarantine (casual sex, adoption of protective measures against the COVID-19 and sexually transmissible infections [STIs], and type and number of sexual partners) and in the period immediately before the emergence of the pandemic (strategies to find partners, type and number of partners and preventive measures against STIs).

In this study, the participants were asked whether they had consumed drugs immediately before and/or during sexual intercourse since restrictive measures had been imposed in Portugal. Those who answered "yes" were asked to check the drugs consumed in a multiplechoice list. Considering there is not a universally accepted definition of what drugs compose the "chemsex phenomenon"(28-29), in this study, both legal and illegal drugs that alter an individual's perception and lead to the neglect of protective measures against SARSCoV-2 were included: alcohol; opioids (e.g., heroin, codeine and other synthetic substances); cannabinoids (marijuana, hashish, synthetic cannabinoids, spice); sedatives or hypnotics (barbiturates, benzodiazepines); cocaine; stimulants (e.g., amphetamines); hallucinogens (LSD; ecstasy); sex-performance-enhancing drugs (poppers) and others. To facilitate the identification and discrimination of drugs, some drugs were identified by other nomenclatures commonly used in Portugal. We also included an open category, "other drugs," in which the participants could specify the drug used if it was not already listed.

Social distancing measures (also called, by the participants as social isolation and/or quarantine) were defined as avoiding personal contact for non-essential activities with people outside one's shelter ${ }^{(10)}$ and an assessment and measurement of compliance to measures followed the literature's guidelines ${ }^{(10,26,30-31)}$.

\section{Data analysis and treatment}

Data were analyzed using the Statistical Package for the Social Sciences - SPSS v.26. Descriptive statistics such as absolute and relative frequencies were considered. Bivariate and multivariate analyses were performed with the chemsex practice being the dependent variable and sociodemographic variables, sexual behavior and strategies to prevent COVID-19 as the independent 
variables. Tolerance coefficients and VIF (Variance Inflation Factor) were verified to assess multicollinearity and proceed with the multivariate analysis. Odds Ratio (OR) and adjusted Odds Ratio (aOR) were used to measure the intensity of association between chemsex and associated factors considering their respective 95\% confidence intervals. The model was developed using the stepwise method and the best goodness of fit and performance, according to the Hosmer and Lemeshow test, were considered.

\section{Ethical aspects}

The Institutional Review Board at the Instituto de Higiene e Medicina Tropical (IHMT) at the Universidade Nova de Lisboa approved the study (protocol 1219/2020).

\section{Results}

A total of 1,301 MSM took part in the study. The participants were aged 30.5 years old on average (standard deviation=9.2; minimum 18 and maximum 66 years old) with a median of 1 sexual partner (minimum: 0 - maximum: 32) during the period of social isolation. Chemsex was reported by $20.2 \%(n=263)$ of the participants; all of whom $(n=263)$ reported casual sex, and slightly less than half $(44.9 \% ; n=118)$ did not used condoms during sexual intercourse. Most sex partners practicing chemsex were found through dating apps (81.4\%; $n=214)$. Approximately $30 \%(n=356)$ of the participants used pre-exposure prophylaxis (PrEP/Truvada) against Human Immunodeficiency Vírus (HIV), as shown in Table 1.

Table 1 - Social, demographic and sexual health characterization of men who have sex with men (n: 1,301). Portugal, 2020

\begin{tabular}{|c|c|c|c|c|c|c|c|}
\hline \multirow{3}{*}{ Interest variable } & \multicolumn{4}{|c|}{ Chemsex ${ }^{*}$} & \multirow{3}{*}{$\begin{array}{c}\text { Total } \\
\mathbf{N}\end{array}$} & \multirow{3}{*}{$\%$} & \multirow{3}{*}{$\mathbf{p}^{\dagger}$} \\
\hline & \multicolumn{2}{|c|}{ Yes } & \multicolumn{2}{|c|}{ No } & & & \\
\hline & $n$ & $\%$ & $\mathrm{n}$ & $\%$ & & & \\
\hline \multicolumn{8}{|l|}{ Sociodemographic characteristics } \\
\hline Age (years old) & & & & & & & 0.001 \\
\hline$<35$ & 207 & 21.3 & 763 & 78.7 & 970 & 74.5 & \\
\hline$\geq 35$ & 56 & 16.9 & 275 & 83.1 & 331 & 25.4 & \\
\hline Gender identity & & & & & & & 0.096 \\
\hline Cisgender man & 251 & 19.6 & 1030 & 80.4 & 1281 & 98.4 & \\
\hline Transgender man & 12 & 60 & 8 & 40 & 20 & 1.6 & \\
\hline Education (complete years) & & & & & & & 0.001 \\
\hline$\leq 9$ & 52 & 77.5 & 311 & 85.7 & 363 & 27.9 & \\
\hline$>9$ & 211 & 22.5 & 727 & 14.3 & 938 & 72.1 & \\
\hline \multicolumn{8}{|l|}{ Lives in the metropolitan region } \\
\hline Yes & 252 & 95.8 & 955 & 92 & 1207 & 92.8 & \multirow{2}{*}{0.033} \\
\hline No & 11 & 4.2 & 83 & 8 & 94 & 7.2 & \\
\hline Current relationship & & & & & & & 0.001 \\
\hline Stable & 28 & 10.6 & 173 & 16.7 & 201 & 15.5 & \\
\hline Open/polyamory & 7 & 2.7 & 82 & 7.9 & 89 & 6.8 & \\
\hline Single & 228 & 867 & 783 & 75.4 & 1011 & 77.7 & \\
\hline Live with sexual partner & 18 & 6.8 & 149 & 14.4 & 167 & 18.6 & 0.001 \\
\hline Use dating apps to seek partners & 214 & 81.4 & 774 & 74.6 & 988 & 75.9 & 0.021 \\
\hline \multicolumn{8}{|l|}{ Sexual health } \\
\hline Tested for $\mathrm{HIV}^{\ddagger}$ in the last 12 months & 106 & 40.3 & 559 & 39.3 & 665 & 57.1 & 0.239 \\
\hline \multicolumn{8}{|l|}{ HIV ${ }^{\ddagger}$ diagnosis } \\
\hline Unknown & 12 & 4.6 & 124 & 11.9 & 136 & 10.4 & \\
\hline $\mathrm{HIV}^{\ddagger}$ - & 206 & 78.3 & 728 & 70.1 & 934 & 71.8 & 0.002 \\
\hline $\mathrm{HIV}^{\ddagger}+$ & 45 & 17.1 & 186 & 17.9 & 231 & 17.8 & \\
\hline Use PrEP\$ / Truvadall & 104 & 29.2 & 252 & 70.8 & 356 & 30.6 & 0.001 \\
\hline
\end{tabular}

${ }^{*}$ Chemsex = Sex under the influence of drugs; ${ }^{\dagger} p=$ Statistical significance obtained through a Chi-square test; ${ }^{*}$ HIV = Human Immunodeficiency Virus; ${ }^{5}$ PrEP = Pre-exposure Prophylaxis; "Truvada = brand name for the combination of tenofovir disoproxil fumarate (TDF - $300 \mathrm{mg})$ and emtricitabine (FTC - $200 \mathrm{mg}$ ) 
Behaviors adopted during social distancing measures imposed to prevent the spread of COVID-19 seem to be associated with chemsex. The following variables stand out: the number of partners $(p<0.001)$, HIV status $(p=0.002)$, unprotected sex $(p<0.001)$, group sex $(p<0.001)$ and the adoption of preventive measures to avoid COVID-19, such as: to avoid kissing during sexual intercourse $(p=0.003)$, hand washing during encounters $(p=0.003)$, the use of PrEP $(p<0.001)$ and COVID-19 testing $(p<0.001)$, as shown in Table 2.

Table 2 - Descriptive characteristics of sexual practice among men who have sex with men (n: 1,301$)$ during the COVID-19 pandemic, considering chemsex*. Portugal, 2020

\begin{tabular}{|c|c|c|c|c|c|c|c|}
\hline \multirow{3}{*}{ Interest variables } & \multicolumn{6}{|c|}{ Chemsex ${ }^{*}$} & \multirow{3}{*}{ p-value ${ }^{\dagger}$} \\
\hline & \multicolumn{2}{|c|}{ Yes } & \multicolumn{2}{|c|}{ No } & \multicolumn{2}{|c|}{ Total } & \\
\hline & $\mathrm{n}$ & $\%$ & $\mathbf{n}$ & $\%$ & N & $\%$ & \\
\hline \multicolumn{8}{|l|}{ Social distancing period } \\
\hline Duration of social isolation/distancing (days) & & & & & & & 0.060 \\
\hline Less than 29 & 44 & 16.7 & 114 & 11 & 158 & 12.1 & \\
\hline Between 30 and 45 & 116 & 44.1 & 502 & 48.4 & 618 & 47.5 & \\
\hline More than 45 & 88 & 33.5 & 374 & 36 & 462 & 35.5 & \\
\hline Did not adhere to social isolation & 15 & 5.7 & 48 & 4.6 & 63 & 4.9 & \\
\hline \multicolumn{7}{|c|}{ How many partners did you have since social distancing measures were imposed? } & 0.001 \\
\hline None & 0 & 0 & 466 & 44.9 & 466 & 35.8 & \\
\hline 1 partner & 20 & 7.6 & 397 & 38.2 & 417 & 32.0 & \\
\hline More than 2 & 243 & 92.4 & 175 & 16.9 & 418 & 32.2 & \\
\hline \multicolumn{8}{|l|}{ During the social distancing you: } \\
\hline Had sex with penetration without condoms & 145 & 55.1 & 121 & 11.7 & 266 & 20.5 & 0.001 \\
\hline Paid for sexual intercourse & 16 & 6.1 & 35 & 3.4 & 51 & 3.9 & 0.043 \\
\hline $\begin{array}{l}\text { Group sex (sex with } 2 \text { or more people } \\
\text { simultaneously) }\end{array}$ & 156 & 59.3 & 35 & 3.4 & 191 & 14.7 & 0.001 \\
\hline \multicolumn{8}{|c|}{ Protective measures adopted in casual sex to prevent COVID-19 } \\
\hline Avoided kissing during sexual intercourse & 147 & 55.9 & 195 & 18.8 & 342 & 48.7 & 0.003 \\
\hline Sanitized the place where you had sex & 143 & 54.4 & 198 & 19.1 & 344 & 48.8 & 0.017 \\
\hline Washed hands with water and soap & 148 & 56.3 & 197 & 19 & 345 & 49.9 & 0.003 \\
\hline $\begin{array}{l}\text { Verified whether the sexual partner had signs and } \\
\text { symptoms of COVID-19 }\end{array}$ & 158 & 60.1 & 457 & 35.1 & 615 & 63.7 & 0.031 \\
\hline Used PrEP / Truvada & 112 & 42.6 & 64 & 6.2 & 176 & 25.1 & 0.001 \\
\hline \multicolumn{8}{|l|}{ COVID-19 testing } \\
\hline Yes & 83 & 31.6 & 167 & 16.1 & 250 & 19.2 & \multirow{2}{*}{0.001} \\
\hline No & 180 & 68.4 & 871 & 83.9 & 1051 & 80.8 & \\
\hline \multicolumn{8}{|l|}{ Diagnosed with COVID-19 } \\
\hline Yes & 41 & 15.6 & 58 & 5.6 & 99 & 39.6 & \multirow{2}{*}{0.026} \\
\hline No & 42 & 16 & 109 & 10.5 & 151 & 60.4 & \\
\hline
\end{tabular}

${ }^{*}$ Chemsex $=$ Sex under the influence of drugs; ${ }^{\dagger} p=$ Statistical significance obtained through a Chi-square test; ${ }^{*}$ HIV = Human immunodeficiency Virus; SPrEP $=$ Pre-exposure Prophylaxis

Bivariate and multivariate logistic regression was used and the following factors appeared associated with chemsex during the COVID-19 pandemic among Portuguese MSM. Those who practiced group sex during quarantine measures were 28 times more likely to engage in chemsex, while those who tested for COVID-19 were
1.9 times more likely to engage in chemsex. Those MSM who had sex without protection were 7.1 times more likely to engage in chemsex, while those who reported PrEP as a way to prevent COVID-19 were 4.2 times more likely to engage in chemsex (Table 3 ). 
Table 3 - Bivariate and multivariate analyses considering men who have sex with men $(n: 1,301)$ reporting chemsex during the COVID-19 pandemic. Portugal, 2020

\begin{tabular}{|c|c|c|c|c|c|c|}
\hline Variables & $\mathrm{OR}^{*}$ & p-value ${ }^{\dagger}$ & $95 \% \mathrm{Cl}^{\ddagger}$ & $\mathrm{aOR} \S$ & p-value ${ }^{\dagger}$ & $95 \% \mathrm{CI}^{\ddagger}$ \\
\hline \multicolumn{7}{|c|}{ Sociodemographic characteristics } \\
\hline \multicolumn{7}{|c|}{ Current relationship } \\
\hline Stable & 1 & & & & & \\
\hline Polyamory/open & 0.52 & 0.145 & $0.22-1.25$ & & & \\
\hline Single & 1.79 & 0.007 & $1.17-2.75$ & & & \\
\hline \multicolumn{7}{|c|}{ Live with sexual partner } \\
\hline Yes & 1 & & & & & \\
\hline No & 2.42 & 0.001 & $1.44-4.07$ & & & \\
\hline \multicolumn{7}{|c|}{ Live in the metropolitan area } \\
\hline No & 1 & & & & & \\
\hline Yes & 1.99 & 0.030 & $1.04-3.79$ & & & \\
\hline \multicolumn{7}{|c|}{ Use dating apps to seek partners } \\
\hline No & 1 & & & & & \\
\hline Yes & 1.49 & 0.022 & $1.06-2.09$ & & & \\
\hline \multicolumn{7}{|l|}{ Sexual health } \\
\hline \multicolumn{7}{|l|}{ HIV $\|$ Status } \\
\hline Unknown & 1 & & & & & \\
\hline HIVII - & 2.92 & 0.001 & $1.58-5.39$ & & & \\
\hline $\mathrm{HIV} \|+$ & 2.50 & 0.005 & $1.27-4.91$ & & & \\
\hline \multicolumn{7}{|c|}{ During the social distancing period } \\
\hline \multicolumn{7}{|c|}{$\begin{array}{l}\text { Group sex (with } 2 \text { or more people } \\
\text { simultaneously) }\end{array}$} \\
\hline No & $\begin{array}{c}1 \\
170\end{array}$ & 001 & $2752-6341$ & 284 & 001 & $1693-4749$ \\
\hline Yes & 41.78 & 0.001 & $27.52-63.41$ & 28.4 & 0.001 & $16.93-47.49$ \\
\hline \multicolumn{7}{|c|}{ Sex with penetration without condoms } \\
\hline \multicolumn{7}{|c|}{ No } \\
\hline Yes & 9.31 & 0.001 & $6.84-12.67$ & 7.1 & 0.001 & $4.57-10.99$ \\
\hline \multicolumn{7}{|c|}{ Paid for sexual intercourse } \\
\hline No & 1 & & & & & \\
\hline Yes & 1.85 & 0.040 & $1.01-3.40$ & & & \\
\hline
\end{tabular}

Protective measures against the COVID-19 adopted during casual sex

Disinfected the place where you had sex

No

Yes

Avoided kissing during sexual intercourse?

No

Yes 1.58

Verified whether the sexual partner had

signs and symptoms of COVID-19

No

$\begin{array}{llll}\text { Yes } & 1.41 & 0.031 & 1.03-1.95\end{array}$

Used PrEPा / Truvada

No

$\begin{array}{lllllll}\text { Yes } & 4.34 & 0.001 & 3.03-6.23 & 4.2 & 0.001 & 2.71-6.39\end{array}$

COVID-19 Investigation

COVID-19 testing

No

$\begin{array}{lllllll}\text { Yes } & 2.40 & 0.001 & 1.76-3.27 & 1.9 & 0.012 & 1.15-3.10\end{array}$

${ }^{*} \mathrm{OR}=$ Odds Ratio; ${ }^{\dagger} p=$ Statistical significance; ${ }^{\ddagger} 95 \% \mathrm{CI}=95 \%$ Confidence Interval; ${ }^{\S} \mathrm{aOR}=$ adjusted Odds Ratio; "HIV = Human Immunodeficiency Virus; IPrEP $=$ Pre-exposure prophylaxis. Hosmer and Lemeshow test $(p=0.61)$

\section{Discussion}

The data from this study show a high frequency of chemsex $(20.2 \%)$ in this population, considering the results reported by a research addressing this same population before the pandemic $(9.2 \%)^{(29)}$. In this sample, one in every four MSM engaged in casual sex using at least one substance capable of changing cerebral functioning and altering an individual's mental and psychological state. These results are generally of concern; however, they are 
even more critical considering that the chemsex practice increased ${ }^{(10,29-30)}$ precisely when the epidemiological curve of the first wave of COVID-19 in Portugal (April and May 2020) was ascending.

The large portion of MSM who reported chemsex during the social isolation period in the country may be related to the fact that data were collected only a few days after the first state of emergency was issued in Portugal, when some of the participants behaved the same as to the period before the pandemic. Throughout the prolonged period of social distancing, psychological disorders such as anxiety and depression ${ }^{(32-33)}$ became evident and casual sex with unknown partners, drug use and multiple partners may have been adopted as a way to "relax and escape from reality" even if for a short period and with risks.

Among the factors that increase the chances of MSM engaging in chemsex, goup sex (with 2 or more people simultaneously) stood out as conferring a 28 times greater chance than among those who did not report sex group. This is a classic relationship reported in the literature, in which studies ${ }^{(34-35)}$ report that group sex is usually associated with the use of drugs, regardless of the type of drug, though those that enhance sexual performance, such as mephedrone, methamphetamine and/or GHB/ GBL stand out.

Those practicing chemsex associated it with significant improvements in quality of life and sex performance because it decreases inhibition and increases sexual arousal and pleasure. The combination of drugs, long sex sessions, and multiple partners also leads to even more challenging sexual practices such as fisting and duple penetration ${ }^{(36)}$. This finding highlights the possibility of overlapping exposure and synergistic epidemic, considering that the use of drugs may hinder adherence to measures intended to prevent Sexually Transmitted Infections (STIs) while simultaneously, the reunion of people with different levels of exposure to SARS-CoV- 2 in the same place for a high amount of time may increase the likelihood of being contaminated by the novel coronavirus ${ }^{(36-37)}$.

One finding that illustrates this situation is that the practice of anal sex without condoms increased 7.1 times the likelihood of an individual engaging in chemsex. This piece of information reinforces that MSM who practice chemsex might be more willing to engage in risky behavior. The use of illegal or legal drugs in a sexual context leads to decreased discernment among vulnerable populations such as MSM, considering they are more likely to acquire HIV and STIs, highlighting the risks they are exposed to ${ }^{(29)}$. In a context of the coronavirus pandemic, the likelihood of new cases emerging among the Portuguese population increase due to sexual behavior and a high risk of acquiring the COVID-19(14).
This study's results corroborate previous studies ${ }^{(38-41)}$, which report that the use of drugs in a sexual context considerably increases risky behaviors (unprotected sexual intercourse) due to decreased risk perception. Hence, MSM who practice chemsex are more likely to acquire HIV and other STIs, to practice group sex or sex with more than one partner in the same night, to decrease adherence to the antiretroviral treatment among HIV positive patients and to protective measures such as de PrEP, which was reported by approximately $30 \%$ of the MSM addressed in this study.

However, the sample of MSM addressed in this study adopted PrEP not only to prevent HIV. This group, mistakenly, adopted PrEP as a way to prevent SARSCoV-2 as well. These individuals' chances to engage in chemsex increased 4.1 times, a result that was also found among Brazilian MSM(11). The hypothesis ${ }^{(10)}$ is that, given the misunderstanding reported by the mass media and social media, such as Facebook, concerning the prophylactic medications' potential to fight SARS-CoV-2(42), some MSM may have confused the PrEP strategy. That is, they assumed the HIV pre-exposure prophylaxis had a similar effect (prophylaxis) against the SARS-CoV-2, which may have motivated the maintenance of sexual practices during the pandemic.

These beliefs may also have been influenced by the dissemination of recent preliminary studies ${ }^{(43-44)}$ conducted in Brazil investigating the potential of Tenofovir, one of the antiretroviral drugs used in Truvada, to decrease the length of hospitalizations due to SARS-CoV-2. Such information enhances the ability of fake news to spread on social media. Since there is no evidence it prevents COVID-19, there is an increased risk of people using PrEP neglecting the effective protective measures ${ }^{(45)}$ recommended by sanitary agencies during the social isolation and being infected with SARS-CoV-2.

Another questionable measure, but which increased the likelihood of MSM engaging in chemsex, is based on the COVID-19 testing as those who reported testing for COVID-19 were, almost, 2 times more likely to engage in chemsex than those who did not.

We believe that the testing may lead to a false sense of security. A belief that individuals who tested positive for COVID-19 acquire immunity against the disease, hence would not be re-infected, may have led MSM to take more risks. However, this is a misleading belief, considering that it is unknown how immunological memory ${ }^{(46-47)}$ works with this new infection or what its efficacy is. Additionally, the literature has already reported re-infection by different strains $^{(48)}$ of the same virus.

On the other hand, the participants who tested negative for COVID-19 may have been encouraged to have sex with unknown partners for believing that "they 
do not get infected", especially when signs and symptoms of COVID-19 were absent. The literature corroborates this finding. A Brazilian study reports that MSM who tested recently were more prone to engage in casual sex. Among the measures adopted to manage the risk of acquiring SARS-Cov-2, verifying that partners did not present signs and symptoms of COVID-19 was determinant for maintaining sexual encounters ${ }^{(12)}$.

The findings of this study are unprecedented in the literature and, coupled with other similar(10-12), raised questions regarding the actual role and impact of sexual behavior and the maintenance of certain risky behaviors (e.g., casual sex, group sex, with the use of drugs or without condoms) on the current COVID-19 pandemic. This panorama shows that good mitigation strategies (social distancing/isolation or quarantine) pervade messages addressing sexual issues and vulnerable populations. Disseminating information regarding the practice and use of less harmful drugs with a decreased number of people or at least decreased sexual partner turnover and, simultaneously, encouraging preventive measures against STIs and COVID-19 may be effective.

This study presents some limitation. The first referred to the impossibility of establishing a causal relationship between the practice of chemsex and SARS-COV-2 infection or stating that the maintenance of isolation measures increased the occurrence of risky sexual behavior for STIs or COVID-19. The online collection of data was based on self-reported data, addressing an accidental sample and even though mechanisms were used to diversify the sample, a lack of a more robust sampling calculation (e.g., cluster sampling) restricts the inference of results in addition to the possible restriction among participants who were more familiar, and with greater access, to virtual tools. These findings should be interpreted with caution, primarily because behaviors and circumstances related to the COVID-19 may change suddenly.

\section{Conclusion}

The occurrence of chemsex among MSM during the COVID-19 pandemic in Portugal was very high, showing an increase in its prevalence. It indicates that the worldwide health calamity did not sensitize Portuguese MSM to adhere to restrictive and social distancing measures. Aspects such as age, education, gender identity, type of relationship, the adoption of dating apps, HIV and COVID-19 testing, duration of isolation, number of sexual partners, sexual behavior during the quarantine and protective measures against the COVID-19 were significantly associated with chemsex among MSM in Portugal. These results reveal that it is impossible to ignore the role of sexual and loving relationships and activities on the adherence to social distancing measures and the magnitude of the pandemic itself, especially among socially marginalized groups such as MSM.

We suggest that messages recommending preventive measures against the COVID-19 explicitly target sexual behavior and its consequences for the aggravation of the current pandemic context be part of governmental actions.

\section{References}

1. Andersen KG, Rambaut A, Lipkin WI, Holmes EC, Garry RF. The proximal origin of SARS-CoV-2. Nat Med. 2020;26(4):450-2. doi: https://doi.org/10.1038/s41591020-0820-9

2. World Health Organization. WHO Coronavirus Disease (COVID-19) Dashboard. [Internet]. 2020. [cited 2020 Sep 13]. Available from: https://covid19.who.int/

3. Albuquerque LP, Silva RB, Araújo RMS. COVID-19: origin, pathogenesis, transmission, clinical aspects and current therapeutic strategies. Rev Prev Infec Saúde. 2020;6:10432. doi: https://doi.org/10.26694/repis. v6i0.10432

4. Duczmal LH, Almeida ACL, Duczmal DB, Alves CRL, Magalhães FCO, Lima MS, et al. Vertical social distancing policy is ineffective to contain the COVID-19 pandemic. Cad Saude Publica. 2020;36(5):1-9. doi: https://doi. org/10.1590/0102-311×00084420

5. Direção Geral de Saúde. COVID-19. Ponto de situação atual em Portugal. [Internet]. 2020 [Acesso 10 abr 2020]. Disponível em: https://covid19.min-saude.pt/ponto-desituacao-atual-em-portugal

6. Cordeiro-Rodrigues L. Social Justice for Public Health: The COVID-19 Response in Portugal. J Bioeth Inq. 2020;17(4):669-74. doi: http://doi.org/10.1007/s11673020-10058-z

7. Triunfol M. High COVID-19 testing rate in Portugal. Lancet Infect Dis. 2020:20(7):783. doi: https://doi. org/10.1016/S1473-3099(20)30499-0

8. Direção Geral de Saúde. COVID-19. Ponto de situação atual em Portugal. [Internet]. 2020 [Acesso 30 dez 2020]. Disponível em: https://covid19.min-saude.pt/ponto-desituacao-atual-em-portugal/

9. Direção Geral de Saúde. COVID-19. Relatório de situação 29-12-2020. [Internet]. 2020 [Acesso 30 dez 2020]. Disponível em: https://covid19.min-saude.pt/wp-content/ uploads/2020/12/302_DGS_boletim_20201229-002.pdf 10. Sousa AFL, Oliveira LB, Queiroz AAFLN, Carvalho HEF, Schneider G, Camargo ELS, et al. Casual Sex among Men Who Have Sex with Men (MSM) during the Period of Sheltering in Place to Prevent the Spread of COVID-19. Int J Environ Res Public Health. 2021 Mar 22;18(6):3266. doi: $10.3390 /$ ijerph18063266 
11. Sousa AFL, Queiroz AAFLN, Lima SVMA, Almeida PD, Oliveira LB, Chone JS, et al. Chemsex practice among men who have sex with men (MSM) during social isolation from COVID-19: multicentric online survey. Cad Saúde Pública. 2020;36(12):e00202420. doi: https://doi. org/10.1590/0102-311x00202420

12. Carvalho HEF, Schneider G, Sousa AR, Camargo ELS, Nunes RV, Possani MA, et al. Suspected COVID-19 flu-like syndrome in men who have sex with men and have been involved in casual sex. Rev Bras Enferm. 2020;73(supl. 2):e20200913. doi: https://doi.org/10.1590/0034-71672020-0913

13. Evers YJ, Van Liere GAFS, Hoebe CJPA, DukersMuijrers NHTM. Chemsex among men who have sex with men living outside major cities and associations with sexually transmitted infections: A cross-sectional study in the Netherlands. PLoS One. 2019;14(5):e0216732. doi: 10.1371/journal. pone.0216732.

14. Torres TS, Bastos LS, Kamel L, Bezerra DRB, Fernandes NM, Moreira RI, et al. Do men who have sex with men who report alcohol and illicit drug use before/during sex (chemsex) present moderate/high risk for substance use disorders? Drug Alcohol Depend. 2020;209:107908. doi: 10.1016/j.drugalcdep.2020.107908.

15. Schecke H, Lea T, Bohn A, Köhler T, Sander D, Scherbaum N, et al. Crystal Methamphetamine Use in Sexual Settings Among German Men Who Have Sex With Men. Front Psychiatry. 2019;10:1-9. doi: https://doi. org/10.3389/fpsyt.2019.00886

16. Tomkins A, George R, Kliner M. Sexualised drug taking among men who have sex with men: a systematic review. Perspect Public Health. 2019;139(1):23-33. doi: https:// doi.org/10.1177/1757913918778872

17. Giorgetti R, Tagliabracci A, Schifano F, Zaami S, Marinelli E, Busardò FP. When "Chems" Meet Sex: A Rising Phenomenon Called "ChemSex". Curr Neuropharmacol. 2017;15(5):762-70. doi: 10.2174/1570159X15666161 117151148.

18. Hojilla JC, Vlahov D, Glidden DV, Amico KR, Mehrotra $M$, Hance $R$, et al. Skating on thin ice: Stimulant use and sub-optimal adherence to HIV pre-exposure prophylaxis. J Int AIDS Soc. 2018;21(3):1-5. https://doi.org/10.1002/ jia2.25103

19. Faul F, Erdfelder E, Lang AG, Buchner A. G*Power 3: a flexible statistical power analysis program for the social, behavioral, and biomedical sciences. Behav Res Methods. 2007 May;39(2):175-91. doi: 10.3758/bf03193146.

20. Hulley SB. Delineando a pesquisa clínica. 4. ed. Porto Alegre: Artmed; 2015.

21.Queiroz AAFLN, Sousa AFL, Araújo TME, Oliveira FBM, Moura MEB, Reis RK. A review of risk behaviors for HIV infection by men who have sex with men through geosocial networking phone Apps. J Assoc Nurses AIDS
Care. 2017;28(5):807-18. doi: https://doi.org/10.1016/j. jana.2017.03.009

22. Queiroz AAFLN, Sousa AFL, Matos MCB, Araújo TME, Reis RK, Moura MEB. Knowledge about HIV/AIDS and implications of establishing partnerships among Hornet ${ }^{\circledR}$ users. Rev Bras Enferm. 2018;71(4):1949-55. doi: https://doi.org/10.1590/0034-7167-2017-0409

23. Sousa AFL, Queiroz AAFLN, Fronteira I, Lapão L, Mendes IAC, Brignol S. HIV Testing Among Middle-Aged and Older Men Who Have Sex With Men (MSM): A Blind Spot? Am J Mens Health. 2019;13(4). doi: https://doi. org/10.1177/1557988319863542

24. Queiroz AAFLN, Matos MCB, Araújo TME, Reis RK, Sousa ÁFL. Sexually transmitted infections and factors associated with condom use in dating app users in Brazil. Acta Paul Enferm. 2019;32(5):546-53. doi: http://dx.doi. org/10.1590/1982-0194201900076

25. Pasquali L. Psicometria. Rev Esc Enferm USP. 2009; 43(spe): 992-9. doi: https://doi.org/10.1590/S008062342009000500002

26. Camargo ELS, Oliveira BIA, Siffoni IF, Sousa AR, Teixeira JRB, Mendes IAC, et al. Low psychological wellbeing in men who have sex with men (MSM) during the shelter-in-place orders to prevent the COVID-19 spread: results from a nationwide study. Sex Res Soc Policy. 2021 Feb 24;1-10. doi: 10.1007/s13178-021-00550-5.

27. Queiroz AAFLN, Sousa AFL, Araújo TME, Brignol S, Reis RK, Fronteira I, et al. High rates of unprotected receptive anal sex and vulnerabilities to HIV infection among Brazilian men who have sex with men. Int J STD AIDS. 2021:956462420968994. doi: 10.1177/0956462420968994.

28. Edmundson C, Heinsbroek E, Glass R, Hope V, Mohammed $H$, White $M$, et al. Sexualised drug use in the United Kingdom (UK): A review of the literature. Int J Drug Policy. 2018;55:131-48. doi: https://doi.org/10.1016/j. drugpo.2018.02.002

29. Guerras JM, Miller JH, Agustí C, Chanos S, Pichon F, Kuske $M$, et al. Association of Sexualized Drug Use Patterns with HIV/STI Transmission Risk in an Internet Sample of Men Who Have Sex with Men from Seven European Countries. Arch Sex Behavior. 2021 Feb;50(2):461-77. https://doi.org/10.1007/s10508-020-01801-z

30. Sanchez TH, Zlotorzynska M, Rai M, Baral SD. Characterizing the Impact of COVID-19 on Men Who Have Sex with Men Across the United States in April, 2020. AIDS Behav. 2020;24(7):2024-32. doi: https:// doi.org/10.1007/s10461-020-02894-2

31. Van Bavel JJ, Baicker K, Boggio PS, Capraro V, Cichocka A, Cikara M, et al. Using social and behavioural science to support COVID-19 pandemic response. Nat Hum Behav. 2020;4:460-71. doi: https://doi.org/10.1038/ s41562-020-0884-z 
32. Perera S, Bourne AH, Thomas S. Chemsex and antiretroviral therapy nonadherence in hiv-positive men who have sex with men: a systematic review. Sex Transm Infect. 2017;93(Suppl 1). doi: https://doi.org/10.1136/ sextrans-2017-053232.240

33. Frankis J, Flowers P, McDaid L, Bourne A. Low levels of chemsex among men who have sex with men, but high levels of risk among men who engage in chemsex: Analysis of a cross-sectional online survey across four countries. Sex Health. 2018;15(2):144-50. doi: https:// doi.org/10.1071/SH17159

34. Melendez-Torres G., Bourne A. Illicit drug use and its association with sexual risk behaviour among MSM: more questions than answers? Sex Transm Dis. 2016;29(1):5863. doi: https://doi.org/10.1097/QCO.0000000000000234 35. Melendez-Torres GJ, Hickson F, Reid D, Weatherburn P, Bonell C. Nested Event-Level Case-Control Study of Drug Use and Sexual Outcomes in Multipartner Encounters Reported by Men Who Have Sex with Men. AIDS Behav. 2016;20:646-54. doi: https://doi.org/10.1007/s10461015-1127-6

36. Yuen KS, Ye ZW, Fung SY, Chan CP, Jin DY. SARS-CoV-2 and COVID-19: The most important research questions. Cell Biosci. 2020;10(1):1-5. doi: https://doi.org/10.1186/ s13578-020-00404-4

37. Starks TJ, Jones SS, Sauermilch D, Benedict M, Adebayo $T$, Cain $D$, et al. Evaluating the impact of COVID-19: A cohort comparison study of drug use and risky sexual behavior among sexual minority men in the U.S.A. Drug Alcohol Depend J. 2020;(6):108260. doi: https://doi.org/10.1016/j.drugalcdep.2020.108260

38. Dolengevich-Segal H, Gonzalez-Baeza A, Valencia J, Valencia-Ortega E, Cabello A, Tellez-Molina MJ, et al. Drug-related and psychopathological symptoms in HIVpositive men who have sex with men who inject drugs during sex (slamsex): Data from the U-SEX GESIda 9416 study. PLoS One. 2019;14(12):1-16. doi: http://dx.doi. org/10.1371/journal.pone.0220272

39. Winstock $A$. New health promotion for chemsex and Y-hydroxybutyrate (GHB). BMJ. 2015;351:6281. doi: https://doi.org/10.1136/bmj.h6281

40. Lai HH, Kuo YC, Kuo CJ, Lai YJ, Chen M, Chen YT, et al. Methamphetamine Use Associated with Non-adherence to Antiretroviral Treatment in Men Who Have Sex with Men. Sci Rep. 2020;10(1):1-8. doi: https://doi.org/10.1038/ s41598-020-64069-2

41. Hawkins B, Armstrong $\mathrm{HL}$, Kesselring S, Rich AJ, Sereda $P$, Howard $T$, et al. Substance use as a mechanism for social inclusion among gay, bisexual, and other men who have sex with men in Vancouver, Canada. Subst Use Misuse. 2020;54(12):1945-55. doi: https://doi.org/10.1 080/10826084.2019.1621901
42. The Development of PrEP for COVID-19 [Internet]. Pharmacy Times, 2020 May 28 [cited Sep 17, 2020]. Available from: https://www.pharmacytimes.com/view/ the-development-of-prep-for-covid-19

43. Bernardes J. Novo processo ampliará produção nacional de antiviral que pode reduzir tempo de internação por covid-19. [Internet]. 2020 [Acesso 8 set 2020]. Disponível em: https://jornal.usp.br/ciencias/novoprocesso-ampliara-producao-nacional-de-antiviral-quepode-reduzir-tempo-de-internacao-por-covid-19/

44. Duan Y, Yao Y, Kumar SA, Zhu HL, Chang J. Current and future therapeutical approaches for COVID-19. Drug Discov Today. 2020;25(8):1545-52. doi: https://doi. org/10.1016/j.drudis.2020.06.018

45. Torres TS, Hoagland B, Bezerra DRB, Garner A, Jalil EM, Coelho LE, et al. Impact of COVID-19 Pandemic on Sexual Minority Populations in Brazil: An Analysis of Social/ Racial Disparities in Maintaining Social Distancing and a Description of Sexual Behavior. AIDS Behav. [Internet]. 2021 Jan;25(1):73-84. doi: 10.1007/s10461-020-02984-1. 46. Allegra A, Di Gioacchino M, Tonacci A, Musolino C, Gangemi S. Immunopathology of SARS-CoV-2 infection: Immune cells and mediators, prognostic factors, and immune-therapeutic implications. Int J Mol Sci. 2020;21(13):1-19. doi: https://doi.org/10.3390/ ijms21134782

47. Sette A, Crotty S. Pre-existing immunity to SARSCoV-2: the knowns and unknowns. Nat Rev Immunol. 2020;20(8):457-8. doi: http://dx.doi.org/10.1038/ s41577-020-0389-z

48. Chu H, Chan W, Tam AR, Fong CH, Yuan S, Tsoi $\mathrm{H}$, et al. COVID-19 re-infection by a phylogenetically distinct SARS-coronavirus- 2 strain confirmed by whole genome sequencing. Clin Infect Dis. 2020;1-25. doi: https://doi. org/10.1093/cid/ciaa1275

\section{Authors' contribution:}

Study concept and design: Inês Fronteira, Álvaro Francisco Lopes Sousa. Obtaining data: Jeremias Salomão Chone, Shirley Verônica Melo Almeida Lima, Inês Fronteira, Ahmed Nabil Shaaban, Maria do Rosário Oliveira Martins, Álvaro Francisco Lopes Sousa. Data analysis and interpretation: Jeremias Salomão Chone, Shirley Verônica Melo Almeida Lima, Inês Fronteira, Isabel Amélia Costa Mendes, Álvaro Francisco Lopes Sousa.

Statistical analysis: Jeremias Salomão Chone, Shirley Verônica Melo Almeida Lima, Ahmed Nabil Shaaban, Maria do Rosário Oliveira Martins, Álvaro Francisco Lopes Sousa. Obtaining financing: Isabel Amélia Costa Mendes, Álvaro Francisco Lopes Sousa. Drafting the manuscript: Jeremias Salomão Chone, Shirley Verônica 
Melo Almeida Lima, Inês Fronteira, Isabel Amélia Costa Mendes, Ahmed Nabil Shaaban, Maria do Rosário Oliveira Martins, Álvaro Francisco Lopes Sousa. Critical review of the manuscript as to its relevant intellectual content: Jeremias Salomão Chone, Shirley Verônica Melo Almeida Lima, Inês Fronteira, Isabel Amélia Costa Mendes, Ahmed Nabil Shaaban, Maria do Rosário Oliveira Martins, Álvaro Francisco Lopes Sousa.

All authors approved the final version of the text.

Conflict of interest: the authors have declared that there is no conflict of interest. Creative Commons (CC BY).

This license lets others distribute, remix, tweak, and build upon your work, even commercially, as long as they credit you for the original creation. This is the most accommodating of licenses offered. Recommended for maximum dissemination and use of licensed materials. 